\title{
Fluência em filtros cerâmicos de $\mathrm{Al}_{2} \mathrm{O}_{3}$
}

\section{(Creep in $\mathrm{Al}_{2} \mathrm{O}_{3}$ ceramic filters)}

\author{
V. R. Salvini, M. D. M. Innocentini, J. A. Rodrigues, V. C. Pandolfelli \\ Universidade Federal de S. Carlos, DEMa \\ Rod. Washington Luiz, km 235, C.P. 676, 13565-905, S. Carlos, SP \\ pvrs@iris.ufscar.br,vicpando@power.ufscar.br
}

\section{Resumo}

O comportamento de fluência em materiais cerâmicos sólidos é afetado pela sua microestrutura. Fundamentalmente, são três os parâmetros que influenciam o comportamento de fluência nestes materiais: o constituinte mineralógico, a fase vítrea e a porosidade. Além destes fatores microestruturais, a fluência em cerâmicas celulares depende também da sua macroestrutura, constituída de um arranjo tridimensional de filamentos sólidos interligados. Assim, a análise dos resultados de fluência nestes materiais compreende duas etapas: na primeira deve-se identificar o modo de deformação dos filamentos cerâmicos (macroestrutura) e na segunda, identificar o(s) mecanismo(s) de fluência da microestrutura através dos parâmetros $n$ (expoente da tensão aplicada) e Q (energia de ativação do processo). Neste trabalho avaliou-se a fluência em filtros cerâmicos de $\mathrm{Al}_{2} \mathrm{O}_{3}$ de 10 ppi sob compressão de 0,$034 ; 0,051$ e $0,068 \mathrm{MPa}$ às temperaturas de 1500,1550 e $1600^{\circ} \mathrm{C}$ ao ar. De acordo com os resultados obtidos, supõese que o modo de deformação por flambagem dos filamentos paralelos a carga aplicada é um dos principais fatores que contribui para o aumento da taxa de deformação do filtro e, portanto, dos valores de n e Q. Além do modo de deformação dos filamentos, observou-se que o tipo de ensaio de fluência (com ou sem troca de carga) também influencia a determinação dos valores de $\mathrm{n}$ e Q.

Palavras-chave: filtros cerâmicos, fluência, alumina.

\begin{abstract}
The creep behavior of solid ceramics is strongly affected by the microstructure. Fundamentally, there are three microstructural features which influence the creep behavior: the mineral content, the flux content and the apparent porosity. Additionally, the creep of cellular ceramics also depends on their macrostructure constituted by a tridimensional array of struts. Therefore, the creep analysis of these materials should consist of two stages. Firstly, identification of the macrostructure deformation mode and secondly, determination of the stress exponent (n) and the activation energy $(Q)$. In this work the analysis of creep under compression of 0.034; 0.051 and $0.068 \mathrm{MPa}$ at 1500, 1550 and $1600{ }^{\circ} \mathrm{C}$ in air was carried out in $\mathrm{Al}_{2} \mathrm{O}_{3}$ filters with 10 ppi. The results suggested that buckling of struts is an important factor to be considered, since it contributes to increase the deformation rate and, therefore, the values of $n$ and $Q$. Besides the struts deformation mode, the way that the creep test is carried out (with or without load change) will influence the determination of $n$ and $Q$ values.
\end{abstract}

Keywords: ceramic filters, creep, alumina.

\section{INTRODUÇÃO}

O ensaio de fluência tradicionalmente avalia a deformação longitudinal de um corpo cerâmico à temperatura e carga constantes. As condições de ensaio (temperatura e carga) são pré-estabelecidas segundo as solicitações de uso do corpo cerâmico ou segundo norma escolhida. De um modo geral, durante este ensaio obtém-se curvas conforme as esquematizadas na Fig. 1. Em um primeiro estágio, os resultados experimentais coletados correspondem à deformação instantânea do corpo $(\varepsilon)$ em função do tempo $(t)$, conforme ilustrado na Fig. 1a. À partir destes dados, calcula-se a taxa de deformação ou de fluência, definida como (dع/dt) ou $(\dot{\varepsilon})$, a qual é plotada em função

da deformação, $\varepsilon$ (Fig. 1b). Normalmente, o gráfico de fluência (Fig. 1b) apresenta três estágios. No estágio primário (I) a taxa de deformação diminui com o tempo. Seguido a este, tem-se o estágio secundário (II) ou estado estacionário, onde a taxa de deformação é constante. E finalmente, o estágio terciário (III) onde a taxa de deformação aumenta acentuadamente até a fratura do corpo-de-prova.

A maioria dos mecanismos de fluência em temperaturas elevadas apresenta um regime de taxa estacionária, $(\mathrm{d} \varepsilon / \mathrm{dt})$ ou $(\dot{\varepsilon})$, expressa segundo a equação:

$$
\dot{\varepsilon}=\mathrm{A} \cdot \sigma^{\mathrm{n}} \cdot \exp \left(-\frac{\mathrm{Q}}{\mathrm{RT}}\right) \cdot \frac{1}{\mathrm{~d}^{\mathrm{p}}}
$$


onde A é um parâmetro microestrutural; $\sigma$, a tensão aplicada; n, o expoente da tensão; Q, a energia de ativação do processo; R, a constante universal dos gases; $\mathrm{T}$, a temperatura em escala absoluta; d, o tamanho de grão e p, o expoente do tamanho de grão.
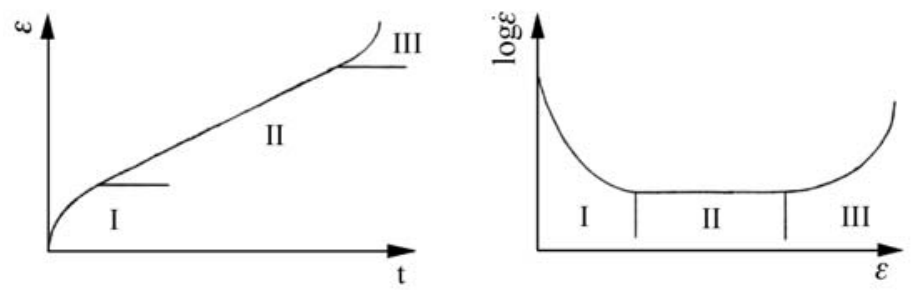

1(a) 1(b)
Figura 1: Esquema de ensaio de fluência: (a) curva de deformação $(\varepsilon)$ versus tempo (t) e (b) curva da taxa de deformação $(\dot{\varepsilon})$ versus deformação ( $\varepsilon$ ) em escala monologaritmica.

[Figure 1: Schematic details for a ceramic creep test: (a) deformation curve profile as function of time and (b) deformation rate curve profile as function of deformation.]

Segundo a literatura [1-3], o mecanismo de fluência é especificado pelos valores experimentais das grandezas $\mathrm{p}, \mathrm{n}$ e $\mathrm{Q}$ da equação (A).

Ainda segundo a literatura [1-3], o comportamento de fluência de sólidos cerâmicos policristalinos é fortemente afetado pela sua microestrutura. Fundamentalmente, são três os parâmetros microestruturais de interesse

- o constituinte mineralógico (tamanho de grão e distribuição dos agregados cristalinos);

- o constituinte vítreo (quantidade relativa, composição e distribuição da fase vítrea) e

- a porosidade aparente.

Já no modelo de fluência desenvolvido por Ashby e Gibson [4, 5] para materiais celulares monofásicos de células abertas tais como os filtros cerâmicos, a taxa de deformação pode ser ainda expressa:

$$
\dot{\varepsilon}=\mathrm{A} \cdot \sigma \cdot\left(\frac{\rho}{\rho_{\mathrm{s}}}\right)^{2} \cdot \exp \left(-\frac{\mathrm{Q}}{\mathrm{RT}}\right)
$$

onde $\left(\rho / \rho_{\mathrm{s}}\right)$ é a densidade relativa do filtro, sendo $\rho$ a densidade geométrica do filtro e $\rho_{\mathrm{s}}$, a densidade teórica do material que constitui os filamentos. Segundo Ashby e Gibson [4, 5] para filtros cerâmicos o expoente de tensão deve ser igual à unidade $(n=1)$ e a taxa de deformação $(\dot{\varepsilon})$ apresenta dependência quadrática com a densidade relativa do filtro $\left(\rho / \rho_{\mathrm{s}}\right)$ e, ainda, independe do tamanho de grão (d) do material cerâmico que constitui o filamento.

Contudo, resultados de fluência em filtros cerâmicos são escassos, embora sejam aplicados sob carga à altas temperaturas. Acredita-se [5] que o primeiro passo no sentido de compreender o comportamento mecânico desta classe de materiais cerâmicos deve ser o de observar a sua peculiar estrutura.

Os filtros cerâmicos de células abertas são produzidos pelo método da réplica de esponjas poliméricas [6], as quais são eliminadas durante a queima deixando, em seu lugar, filamentos ocos. Desse modo, a estrutura de filtros cerâmicos pode ser classificada em dois níveis. No primeiro, a estrutura celular, constituída de um arranjo tridimensional de filamentos ocos, denominada macroestrutura. E em um segundo nível, a estrutura de poros e grãos dentro da fase sólida que constitui a microestrutura. Assim, quando os filtros cerâmicos são solicitados em fluência, a análise dos resultados deve compreender duas etapas.

$\mathrm{Na}$ primeira etapa, deve-se analisar de que maneira a tensão aplicada e o modo de carregamento (compressão ou tração) estão solicitando a macroestrutura e, assim, identificar o modo de deformação dos filamentos cerâmicos.

Em uma segunda etapa, identificar o(s) mecanismo(s) de fluência da microestrutura através da determinação dos parâmetros $n$ (expoente da tensão), p (expoente do tamanho de grão) e de Q (energia de ativação do processo).

Desse modo, com o intuito de contribuir com o estudo de fluência em materiais cerâmicos celulares, são analisados neste trabalho os resultados de fluência dos filtros cerâmicos de 10 ppi (células por polegada linear) de $\mathrm{Al}_{2} \mathrm{O}_{3}$ obtidos sob carga de compressão uniaxial. As curvas de deformação em função do tempo, sob carga constante, foram obtidas em três temperaturas distintas, sendo que em cada temperatura de ensaio fez-se três trocas de carga.

\section{MATERIAIS E MÉTODOS}

Os filtros cerâmicos de $\mathrm{Al}_{2} \mathrm{O}_{3}$ foram produzidos em laboratório pelo método da réplica de uma esponja de poliuretano de $10 \mathrm{ppi}$ [6], onde ppi corresponde ao número de poros por polegada linear. Anteriormente à impregnação das esponjas, estas foram cortadas na forma de um cilindro vazado com altura e diâmetro externo de $50 \mathrm{~mm}$ e diâmetro interno de $12 \mathrm{~mm}$. A alumina utilizada foi a A3000FL da Alcoa Alumínio S.A.. A Tabela I apresenta a análise química desta matéria-prima fornecida pelo fabricante.

Seguida às etapas de impregnação das esponjas e secagem a $100^{\circ} \mathrm{C} / 24 \mathrm{~h}$, os filtros foram pré-queimados à temperatura de $900{ }^{\circ} \mathrm{C} / 1 \mathrm{~h}$ para eliminação dos aditivos orgânicos e da esponja e, posteriormente, sinterizados a $1650^{\circ} \mathrm{C} / 3 \mathrm{~h}$ [7]. Após a sinterização, determinou-se a densidade relativa dos filtros, onde $\rho$ é a densidade geométrica e $\rho_{\mathrm{s}}$, a densidade real dos filamentos moídos medida por picnometria de hélio. A densidade relativa média dos filtros foi igual a $0,18 \pm 0,01 \mathrm{~g} / \mathrm{cm}^{3}$ e a porosidade média $\left[1-\left(\rho / \rho_{\mathrm{s}}\right) \times 100\right]$ igual $82 \pm 1 \%$.

Inicialmente mediu-se a refratariedade sob carga (RUL) dos filtros de $\mathrm{Al}_{2} \mathrm{O}_{3}$ sob carga de $38 \mathrm{~N}(0,034 \mathrm{MPa})$ com o intuito de se determinar a temperatura onde se inicia a deformação permanente das amostras. Tanto os ensaios de refratariedade sob carga quanto os de fluência foram realizados no equipamento RUL 421E da Netzsch em atmosfera oxidante (ar). No gráfico obtido no ensaio de RUL, ilustrado na Fig. 2, verifica-se um regime linear de expansão térmica até a temperatura de $1200{ }^{\circ} \mathrm{C}$ e, acima de $1300{ }^{\circ} \mathrm{C}$, observa-se o início da deformação plástica da amostra, a qual aumenta acentuadamente para temperaturas superiores a $1400{ }^{\circ} \mathrm{C}$. Segundo o critério da norma ISO 1893 a temperatura de refratariedade

Tabela I - Análise química da $\mathrm{Al}_{2} \mathrm{O}_{3}$ A-3000FL da Alcoa Alumínio S. A. (\%-peso).

[Table I - Alumina chemical analysis (A-3000FL, Alcoa).]

\begin{tabular}{lccccc}
\hline Matéria-prima & $\mathrm{Al}_{2} \mathrm{O}_{3}$ & $\mathrm{SiO}_{2}$ & $\mathrm{Fe}_{2} \mathrm{O}_{3}$ & $\mathrm{Na}_{2} \mathrm{O}$ & $\mathrm{CaO}$ \\
\hline $\mathrm{Al}_{2} \mathrm{O}_{3} \mathrm{~A}-3000 \mathrm{FL}$ & 99,9 & 0,02 & 0,02 & 0,05 & 0,04 \\
\hline
\end{tabular}




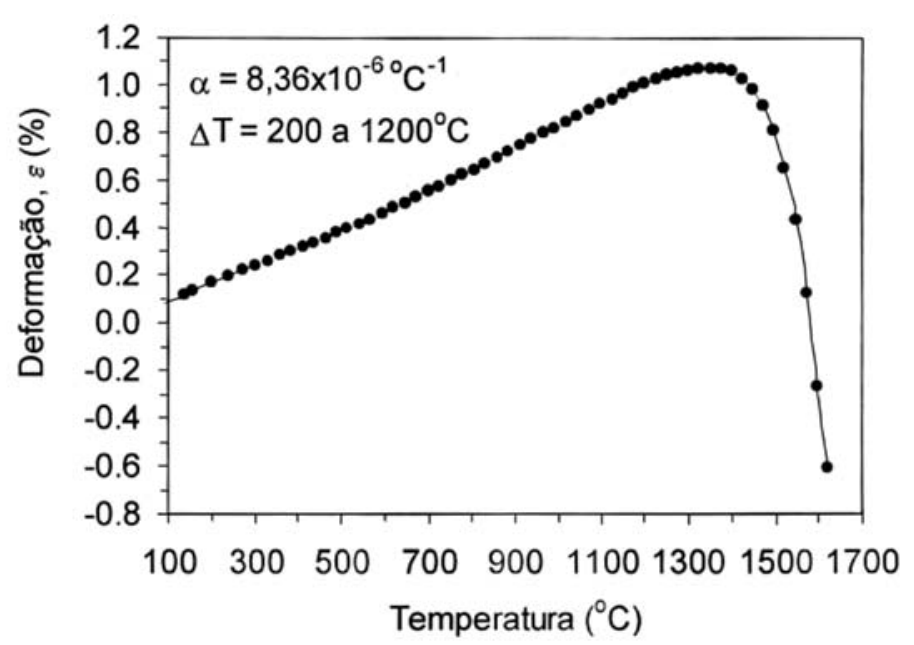

Figura 2: Gráfico de refratariedade sob carga (RUL) do filtro cerâmico de $\mathrm{Al}_{2} \mathrm{O}_{3}$ de 10 ppi.

[Figure 2: Refractoriness-under-load (RUL test) of 10 ppi $\mathrm{Al}_{2} \mathrm{O}_{3}$ filter.]

dos filtros, ou seja, onde verifica-se $0,50 \%$ de deformação permanente, é superior a $1500^{\circ} \mathrm{C}$.

À partir destes resultados, selecionou-se três temperaturas distintas de ensaio de fluência $\left(1500,1550\right.$ e $\left.1600{ }^{\circ} \mathrm{C}\right)$. No equipamento utilizado a deformação a quente das amostras pode ser feita sob carga de compressão constante ou com troca de carga, mas não é possível a troca de temperatura durante o ensaio. Assim, os testes de fluência neste trabalho foram realizados com troca de carga.

As curvas de deformação permanente instantânea em função do tempo (Ext) foram obtidas às temperaturas selecionadas (1500, 1550 e $1600^{\circ} \mathrm{C}$ ), sendo que em cada temperatura de ensaio fez-se três trocas de carga equivalentes a 0,$034 ; 0,051$ e $0,068 \mathrm{MPa}(48$, 72 e $96 \mathrm{~N}$, respectivamente). As cargas de compressão selecionadas para os ensaios de fluência dos filtros correspondem, aproximadamente, ao peso de uma coluna de 17 polegadas de um metal fundido, que é da ordem de $48 \mathrm{~N}$ [7].

A partir dos dados de deformação instantânea obtidos, calculou-se a taxa de deformação (de/dt) e avaliou-se seu comportamento em função da deformação $(\varepsilon)$, conforme esquematizado na Fig. 1b. Da região estacionária deste gráfico, determinou-se a taxa de fluência estacionária média $\left(\mathrm{d} \varepsilon / \mathrm{dt}_{\text {média }}\right)$.

Para determinação dos valores do expoente de tensão (n), plotou-se em um gráfico log-log a taxa de deformação estacionária média $\left(\mathrm{d} \varepsilon / \mathrm{dt}_{\text {média }}\right)$ em função da tensão aplicada $(\sigma)$ obtida às temperaturas de 1500,1550 e $1600{ }^{\circ} \mathrm{C}$. Para determinação da energia de ativação (Q), avaliou-se a taxa de deformação estacionária média $\left(\mathrm{d} \varepsilon / \mathrm{dt}_{\text {média }}\right)$ em função do inverso da temperatura de ensaio $(1 / \mathrm{T})$, obtida para os três níveis de tensão aplicada.

\section{RESULTADOS E DISCUSSÃO}

Na Fig. 3 são apresentadas as curvas de deformação em função do tempo obtidas às temperaturas de 1500,1550 e $1600^{\circ} \mathrm{C}$, respectivamente, com troca de carga. Observa-se que o tempo necessário para atingir uma dada deformação do corpo diminui acentuadamente a medida em que tanto a temperatura de ensaio quanto a carga de compressão aumentam. Por exemplo, se considerarmos que o filtro de $\mathrm{Al}_{2} \mathrm{O}_{3}$ está à temperatura de $1500{ }^{\circ} \mathrm{C}$, o tempo neces-

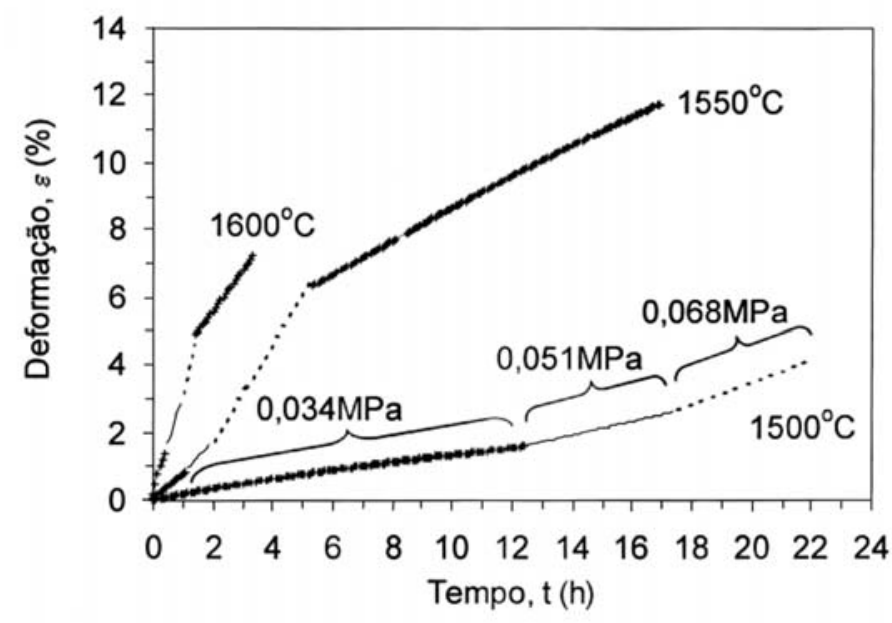

Figura 3: Deformação em função do tempo para o filtro de $\mathrm{Al}_{2} \mathrm{O}_{3}$ de 10 ppi para três temperaturas e três cargas distintas.

[Figure 3: Deformation as function of time, temperature and load for a 10 ppi $\mathrm{Al}_{2} \mathrm{O}_{3}$ filter.]

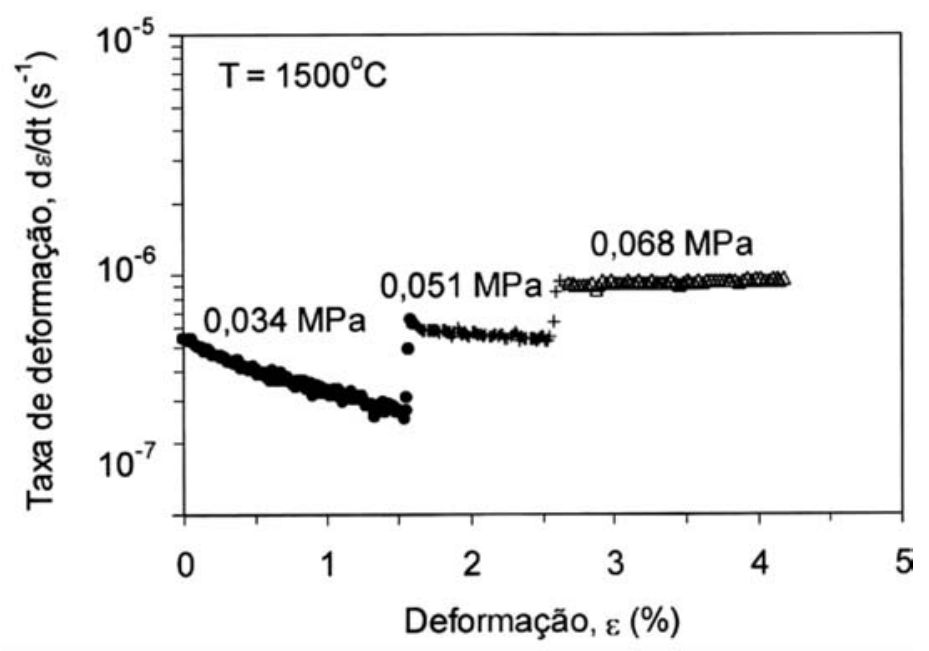

Figura 4: Curvas de fluência para o filtro de $\mathrm{Al}_{2} \mathrm{O}_{3}$ a $1500{ }^{\circ} \mathrm{C}$ com troca de carga de compressão.

[Figure 4: Creep curves of $\mathrm{Al}_{2} \mathrm{O}_{3}$ filter at $1500^{\circ} \mathrm{C}$ with stress change.]

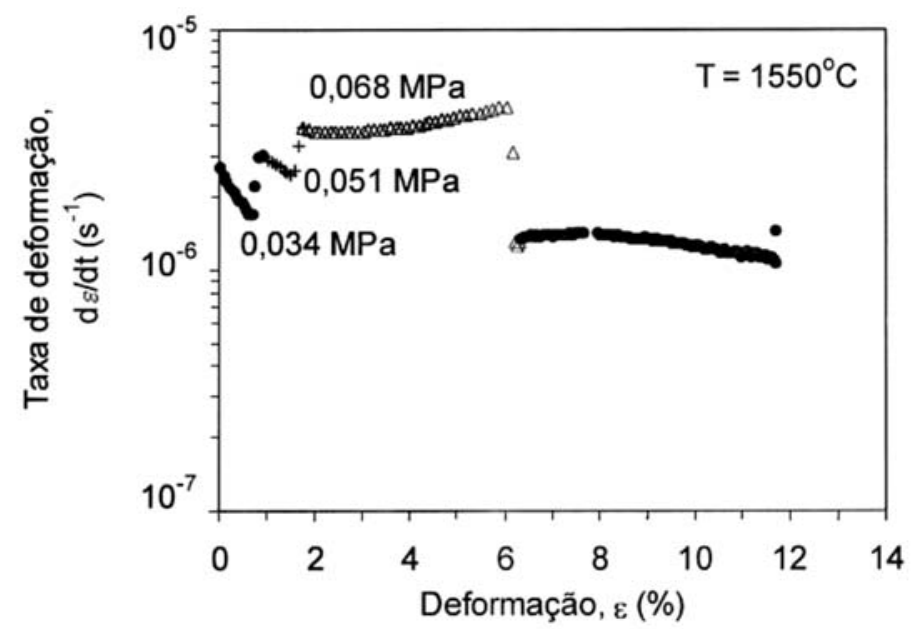

Figura 5: Curvas de fluência para o filtro de $\mathrm{Al}_{2} \mathrm{O}_{3}$ a $1550{ }^{\circ} \mathrm{C}$ com troca de carga de compressão.

[Figure 5: Creep curves of $\mathrm{Al}_{2} \mathrm{O}_{3}$ filter at $1550{ }^{\circ} \mathrm{C}$ with stress change.] 
sário para deformá-lo em 4\% é de 21 horas, enquanto que para atingir esta mesma deformação a $1550{ }^{\circ} \mathrm{C}$ e a $1600{ }^{\circ} \mathrm{C}$ este tempo seria reduzido para 4 e 1,2 horas, respectivamente.

As curvas da taxa de deformação versus deformação $(\mathrm{d} \varepsilon / \mathrm{dt} \times \varepsilon)$, também denominadas de curvas de fluência, obtidas às temperaturas de 1500,1550 e $1600{ }^{\circ} \mathrm{C}$ encontram-se nas Figs. 4,5 e 6 , respectivamente. Nota-se nestas figuras que tanto o aumento da carga como o de temperatura abreviam os estágios II e III (vide esquema da Fig. 1) e a tendência é o estágio estacionário II desaparecer, restando apenas o I e o III. Observe que para a temperatura de $1550{ }^{\circ} \mathrm{C}$, a tensão de 0,068 MPa já é suficiente para a entrada no estágio III da fluência.

Ainda quanto às Figs. 4, 5 e 6, verifica-se que o aumento da temperatura de ensaio, para uma mesma carga, aumenta a taxa de deformação do corpo em torno de uma ordem de grandeza. Como exemplo, a taxa de deformação estacionária do filtro de $\mathrm{Al}_{2} \mathrm{O}_{3}$ sob carga igual a $0,068 \mathrm{MPa}$ e temperatura de $1500{ }^{\circ} \mathrm{C}$ é da ordem de $9 \times 10^{-7} \mathrm{~s}^{-1}$ enquanto que a $1550{ }^{\circ} \mathrm{C}$ a taxa de deformação estacionária foi elevada para $4 \times 10^{6} \mathrm{~s}^{-1}$. Para $1600^{\circ} \mathrm{C}$, a taxa atingiu $1 \times 10^{-5} \mathrm{~s}^{-1}$.

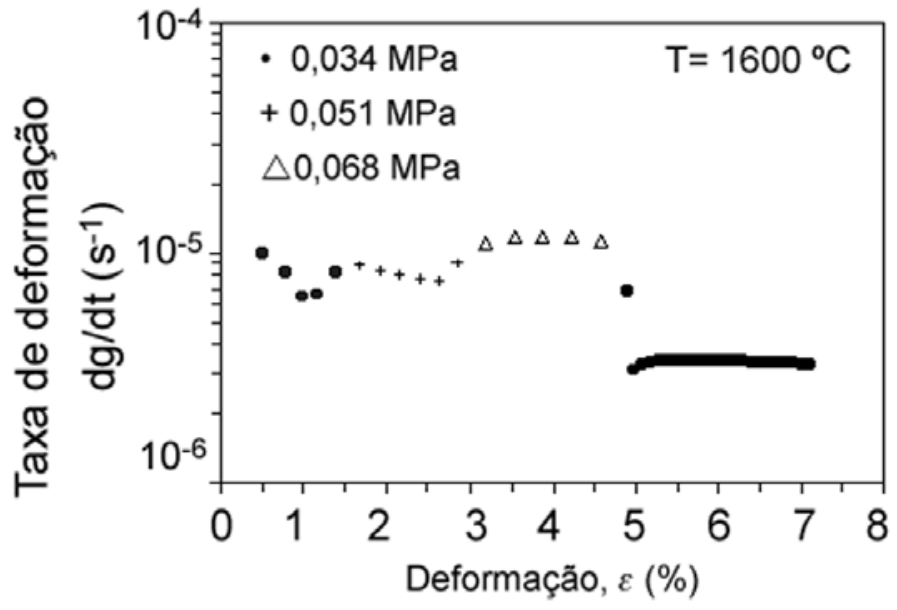

Figura 6: Curvas de fluência para o filtro de $\mathrm{Al}_{2} \mathrm{O}_{3}$ a $1600{ }^{\circ} \mathrm{C}$ com troca de carga de compressão

[Figure 6: Creep curves of $\mathrm{Al}_{2} \mathrm{O}_{3}$ filter at $1600^{\circ} \mathrm{C}$ with stress change.]

Para determinação dos valores do expoente de tensão (n), plotou-se em um gráfico log-log a taxa de deformação estacionária média $\left(\mathrm{d} \varepsilon / \mathrm{dt}_{\text {média }}\right)$ em função da tensão aplicada $(\sigma)$ obtida dos ensaios realizados às temperaturas de 1500,1550 e $1600^{\circ} \mathrm{C}$, conforme ilustrado na Fig. 7.

Observa-se nesta figura que os valores dos expoentes de tensão (n) calculados para os filtros nas temperaturas de ensaio variam entre 1 e 2 , o que segundo a literatura [1-3] é um indicativo de que o mecanismo de fluência predominante nos filtros de $\mathrm{Al}_{2} \mathrm{O}_{3}$ é o de difusão. Sabe-se que para o mecanismo de fluência por difusão a equação (A) apresenta-se nas formas abaixo, dependendo se a difusão do material ocorre através do volume do grão ou se a difusão ocorre pelos contornos-de-grão:

difusão volumétrica (Nabarro-Herring):

$$
\dot{\varepsilon}=\mathrm{A} \cdot\left(\frac{}{\mathrm{R} \mathrm{T}}\right) \cdot \mathrm{D}_{\mathrm{vol}} \cdot \frac{}{\mathrm{d}^{2}}
$$

difusão ao longo do contorno-de-grão (Coble):

$$
\dot{\varepsilon}=\mathrm{A} \cdot\left(\frac{}{\mathrm{R} \mathrm{T}}\right) \cdot \mathrm{D}_{\mathrm{gb}} \cdot \frac{}{\mathrm{d}^{3}}
$$

onde $\Omega$ é a concentração de vacâncias; $\mathrm{D}_{\text {vol }}$, o coeficiente de difusão volumétrico; $\delta$, a espessura do contorno-de-grão e $\mathrm{D}_{\mathrm{gb}}$, o coeficiente de difusão do contorno-de-grão.

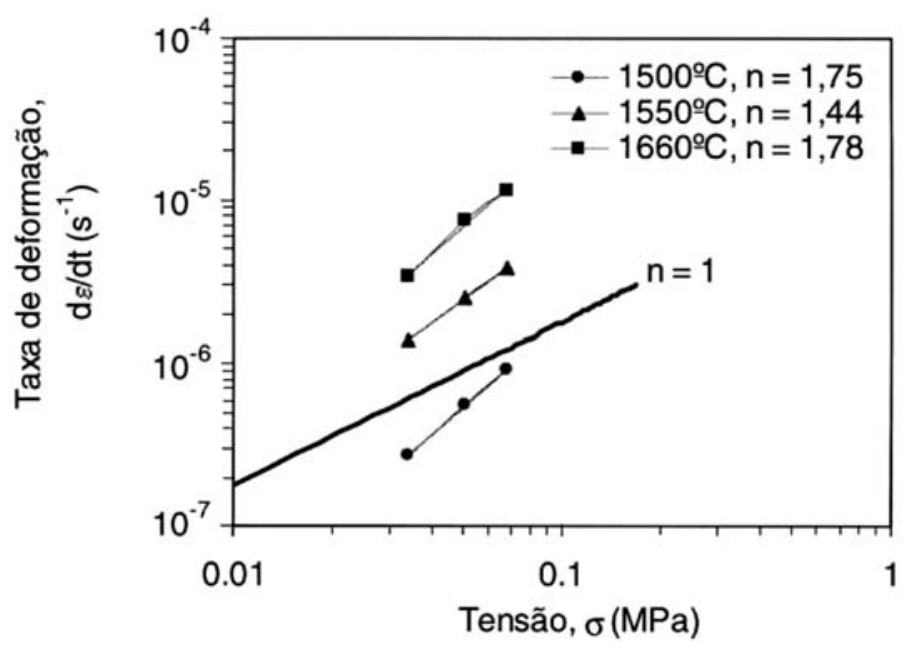

Figura 7: Curvas da taxa de deformação estacionária em função da tensão aplicada obtidas às temperaturas de 1500,1550 e $1600^{\circ} \mathrm{C}$. A reta em preto apresenta inclinação que corresponde a $\mathrm{n}=1$.

[Figure 7: Strain rates versus stress collected at 1500, 1550 e $1600^{\circ} \mathrm{C}$. The black line represents the curve with $n=1$.]

Contudo, se a taxa de deformação fosse unicamente causada pelo mecanismo de difusão, o valor do expoente da tensão deveria ser igual a 1, conforme indicado nas equações $\mathrm{C}$ e D. Estudando o comportamento de fluência de filtros cerâmicos de $\mathrm{Al}_{2} \mathrm{O}_{3}$, curvas da taxa de deformação em função da tensão com o expoente de tensão $\mathrm{n}$ distinto de 1 foram obtidas [8]. Neste trabalho, contudo, não foi feita nenhuma discussão detalhada. Para a compreensão do resultado de $\mathrm{n}>1$, mostrado na Fig. 7 pode-se, a priori, considerar os dados da literatura [1-3] sobre fluência em cerâmicas densas e supor que:

a) a microestrutura do material poderia conter pequenas quantidades de fase vítrea de baixa viscosidade, decorrente da presença de impurezas, e, assim, acelerar a taxa de deformação, ou

b) um outro mecanismo de fluência estaria associado ao de difusão: o mecanismo de escorregamento dos contornos-de-grão onde ocorre a abertura de pequenas cavidades principalmente em pontos triplos, para este mecanismo tem-se $n=2$ e $p=1$.

A hipótese a) não é pertinente aos filtros de $\mathrm{Al}_{2} \mathrm{O}_{3}$ aqui estudados, uma vez que a composição química dos filtros apresenta baixa concentração de impurezas (vide Tabela I) e, portanto, insuficiente para acelerar o processo de deformação por fase vítrea. Quanto à hipótese b), parece também não auxiliar no entendimento dos resultados dos filtros cerâmicos, pois para estes materiais porosos não se considera o efeito do tamanho-de-grão do material, representado pelo parâmetro $\mathrm{p}[4,5]$.

Frente a isso, resta considerar o efeito da carga de compressão aplicada à macroestrutura do filtro, formada por um arranjo tridimensional de filamentos ocos. Nesta linha de análise, pode-se supor que a variação no valor do expoente de tensão $(n>1)$ seja decorrente da flambagem dos filamentos paralelos à carga aplicada.

A flambagem corresponde à deflexão lateral de um corpo delgado, tal como uma coluna, sob carga de compressão uniaxial, conforme esquema ilustrado na Fig. 8 [9]. A flambagem dá-se pelo 
desequilíbrio de forças no corpo e isto ocorre quando a carga aplicada (P) é superior a carga máxima crítica $\left(\mathrm{P}_{\text {crítica }}\right)$ que o corpo suporta. Neste caso, o corpo flamba e não retorna mais a sua posição inicial. Freqüentemente, a flambagem leva a fratura catastrófica da estrutura.

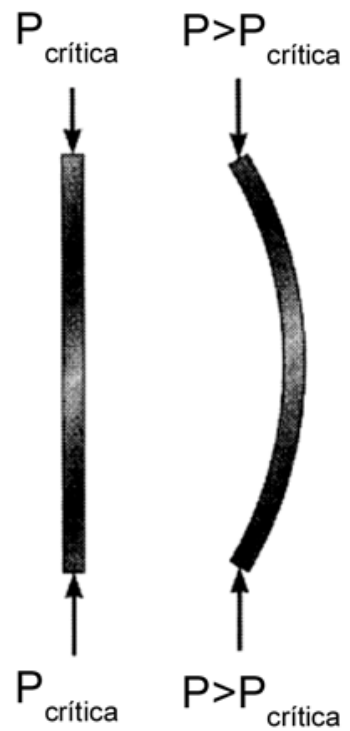

Figura 8: Esquema de flambagem de uma coluna submetida a carga de compressão. A carga máxima que a coluna suporta corresponde a $\mathrm{P}_{\text {critica }}$. A flabagem ocorre quando $\mathrm{P}>\mathrm{P}_{\text {critica }}$ [9].

[Figure 8: Buckling of a column under axial compressive load. The maximum load that a column can support is $P_{\text {critic }}(8 a)$. Any additional loading $\left(P>P_{\text {critic }}\right)$ will cause the column to buckle and therefore deflected laterally (8b) [9].]

Considerando a flambagem dos filamentos verticais de materiais celulares, foi proposto [5] o modelo ilustrado na Fig. 9. Neste modelo o filamento da célula, de comprimento L e espessura $h$, flamba no plano da figura devido a carga de compressão uniaxial F. Ainda, assumiram que o filamento contém imperfeições que induzem à flexão

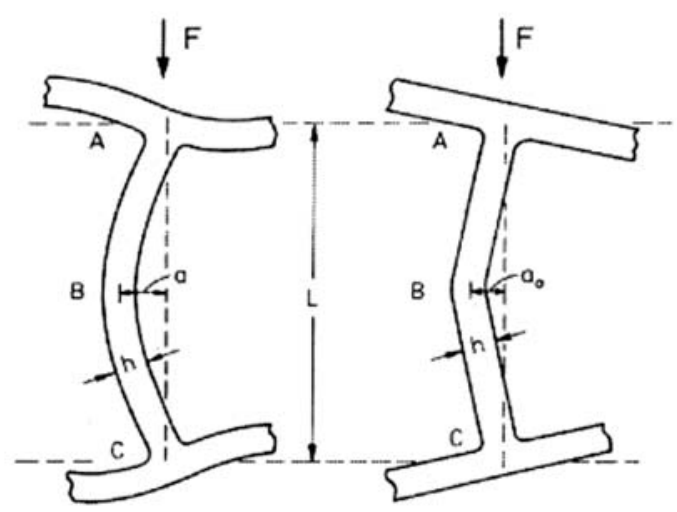

(a)

(b)

Figura 9: Esquema de deformação por flambagem dos filamentos de comprimento L e espessura h paralelos a aplicação da carga $F$ : (a) início e (b) máxima flambagem no centro do filamento [5]. Os pontos A e C correspondem aos pontos de apoio nas extremidades e $\mathrm{B}$, a região central do filamento.

[Figure 9: The creep-buckling of a cell wall under compressive load F: (a) begin and (b) maximum buckling at the wall midpoint [5].] do mesmo na região central, indicada na Fig. 9a por a. Uma vez que a taxa de deformação não é linear, a forma sinuosa do filamento ilustrada na Fig. 9a é rapidamente substituída por aquela apresentada em $9 \mathrm{~b}$, onde a flambagem máxima ocorre em $\mathrm{a}_{0}$.

Dentro deste contexto, supõe-se neste trabalho que a deformação concentrada nos filamentos paralelos à carga aplicada, denominada flambagem, é o fator que está contribuindo para o aumento do expoente da tensão. Contudo, uma quantidade maior de ensaios é necessária para explorar com maiores detalhes este aspecto da fluência em filtros cerâmicos.

A Fig. 10 corresponde ao gráfico de Arrhenius da taxa de deformação estacionária média $\left(\mathrm{d} \varepsilon / \mathrm{dt}_{\text {média }}\right)$ versus o inverso da temperatura de ensaio $(1 / \mathrm{T})$, para os três níveis de tensão aplicada. Observa-se que o valor da energia de ativação $Q$ independe da tensão aplicada $\sigma$. Além disso, o valor médio da energia de ativação $(702 \mathrm{~kJ} / \mathrm{mol})$ é superior ao valor encontrado na literatura para corpos de $\mathrm{Al}_{2} \mathrm{O}_{3}$ policristalina densa (410 a $625 \mathrm{~kJ} / \mathrm{mol}$ na faixa de temperatura de 1450 a $1800^{\circ} \mathrm{C}$ ) [10].

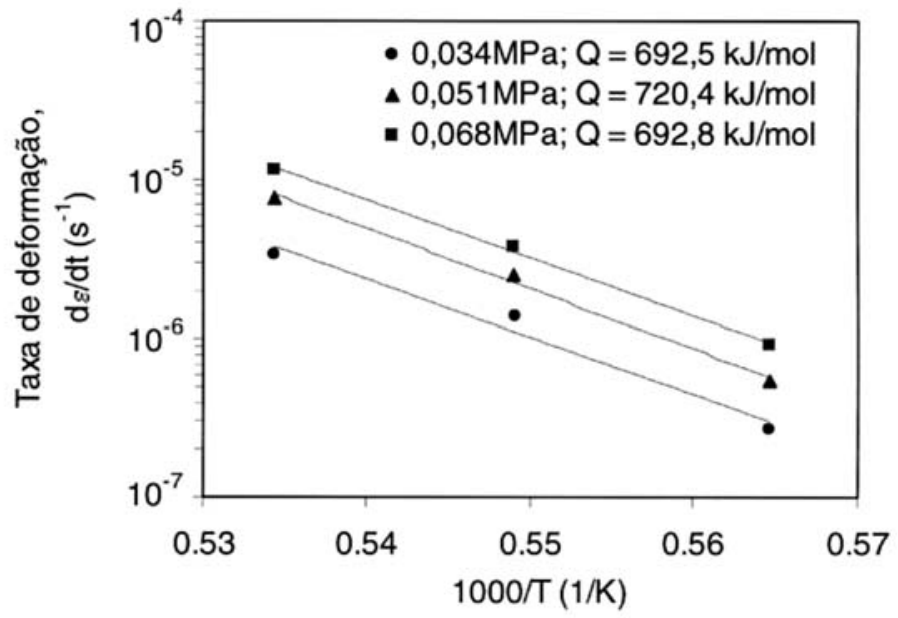

Figura 10: Gráfico de Arrhenius da taxa de deformação estacionária para os filtros de $\mathrm{Al}_{2} \mathrm{O}_{3}$ de 10 ppi.

[Figure 10: Arrhenius diagram for the stationary creep rates.]

Porém, acredita-se que a determinação dos valores de Q e n e, portanto, a definição do(s) mecanismo(s) de fluência em filtros cerâmicos, tem também uma forte dependência com o modo de aplicação da carga nos filamentos durante o ensaio. Para evidenciar este fato, fez-se dois tipos de ensaio de fluência nos filtros de $\mathrm{Al}_{2} \mathrm{O}_{3}$ : um com troca de carga (em um mesmo corpo-de-prova) e outro sem troca de carga nas temperaturas de 1500,1550 e $1600{ }^{\circ} \mathrm{C}$ (em distintos corpos-de-prova). À partir dos dados coletados, calculou-se os valores do expoente de tensão (n) e da energia de ativação (Q). Estes resultados encontram-se na Tabela II.

Tabela II - Valores de n e de Q calculados a partir dos dois tipos de ensaio de fluência sob carga de compressão uniaxial.

[Table II - $n$ and $Q$ values obtained from creep tests with and without stress changes.]

\begin{tabular}{lcc}
\hline Tipo de Ensaio & $\begin{array}{c}\text { Expoente da } \\
\text { tensão, } \mathrm{n}\end{array}$ & $\begin{array}{c}\text { Energia de } \\
\text { ativação, } \mathrm{Q}(\mathrm{kJ} / \mathrm{mol})\end{array}$ \\
\hline Com troca de carga & $1,4-1,8$ & $692-720$ \\
\hline Sem troca de carga & $1,8-2,4$ & $504-684$ \\
\hline
\end{tabular}


A dependência dos valores de $\mathrm{n}$ e $\mathrm{Q}$ com o tipo de ensaio adotado (com ou sem troca de carga) pode ser atribuída à variação das condições das amostras, pois com a troca de carga garante-se que não há mudança da microestrutura do material. Já no ensaio sem a troca de carga pode-se ter variações microestruturais de uma amostra para outra contribuindo, desse modo, para a dispersão das grandezas extraídas.

Além do tipo de ensaio, acredita-se que para filtros cerâmicos a contribuição da deformação por flambagem dos filamentos seja importante no cálculo de n e Q.

No entanto, como há poucos resultados na literatura sobre fluência em cerâmicas celulares, seria importante uma avaliação mais detalhada tanto quanto ao método de ensaio selecionado como o modo de quantificar as contribuições da microestrutura e da flambagem do filamento na determinação dos parâmetros $n$ e Q, que correspondem aos passos futuros na continuidade deste trabalho.

\section{CONCLUSÕES}

As principais conclusões deste trabalho são:

- Os valores dos expoentes de tensão (n) calculados para os filtros nas temperaturas de ensaio variam entre 1 e 2 , sendo, desse modo, um indicativo de que o mecanismo de fluência nos filtros de $\mathrm{Al}_{2} \mathrm{O}_{3}$ não é apenas por difusão.

- Para o caso de filtros cerâmicos, não se pode deixar de considerar também o efeito da sua macroestrutura, formada pelo arranjo tridimensional de filamentos ocos. Assim, é cabível supor que a variação no valor do expoente de tensão $(n>1)$ obtida para os filtros de $\mathrm{Al}_{2} \mathrm{O}_{3}$ seja decorrente da maior taxa de deformação dos filamentos quando a estrutura é submetida a tensões elevadas, uma vez que os mesmos têm apoios rígidos somente nas extremidades. Assim, conclui-se neste trabalho que a deformação por flambagem é o fator que está contribuindo para o aumento do expoente da tensão do filtro.

- A determinação dos valores de Q e n e, portanto, a definição do(s) mecanismo(s) de fluência em filtros cerâmicos de alumina, tem também uma forte dependência com o modo de aplicação da carga durante o ensaio, ou seja, ensaio com ou sem a troca de carga.

\section{AGRADECIMENTOS}

Os autores agradecem ao engenheiro Maurício G. da Silva pelo apoio técnico na realização dos ensaios e à FAPESP, ao CNPq e a Alcoa Alumínio S.A. pelo suporte para a realização deste trabalho.

\section{REFERÊNCIAS}

[1] C. Wolf, R. Kauermann, H. Hübner, J. A. Rodrigues, V. C. Pandolfelli, J. Eur. Ceram. Soc. 15, (1995) 913-929.

[2] S. M. Wiederhorn, R. F. Krause, Am. Ceram. Soc. Bull. 67, 7 (1988) 1201-1210.

[3] W. R. Cannon, T. G. Langdon, J. Mat. Sci. 23, (1988) 1-20.

[4] M. F. Ashby, Metall. Trans. A, 14A, (1983) 1755-1769.

[5] L. J. Gibson, M. F. Ashby, Pergamon Press, $2^{\text {nd }}$. Edition, Oxford (1997).

[6] J. Saggio-Woyansky, C. E. Scott, Am. Ceram. Soc. Bull. 71, 11 (1992) 1674-1682.

[7] V. R. Salvini, M. D. M. Innocentini, V. C. Pandolfelli, Am. Ceram. Soc. Bull. 79, 5 (2000) 49-54.

[8] K. C. Goretta, R. Brezny, C. Q. Dam, D. J. Green, A. R. ArellanoLopéz, A. Dominguez-Rodriguez, Mat. Sci. Eng. A124 (1990) 151-158.

[9] R. C. Hibbeler, Mechanics of Materials, $3^{\text {rd }}$ Edition (1994). [10] E. Dörre, H. Hübner, Springer-Verlag, $1^{\text {st }}$ Edition, Berlin (1984) 154-173.

(Rec. 20/03/01, Rev. 07/01, Ac. 12/10/01) 